replonished as required from beads of hexadeconal housed in a small raft with gauze windows. Because of its enormous potential significance, details of the Mansfield proccss were released at an early stage in its development. This has allowed more experience to be accumulated under different conditions throughout Australia, and widespread use on thousands of dams has confirmed its potential value. However, further use has omphasized that good results are not obtained unless the raft used meets the Commonwealth Scientific and Industrial Research Organization requirements. The condition of the raft must be checked periodically. A recent article discusses some of these practical points, and describes how the few unforeseen difficulties that have cropped up can be overcome (Rural Research in C.S.I.R.O., No, 28 ; June 1959).

\section{Research in the Hat and Feltmaking industries}

THE twelfth annual report of the Director of Research, British Hat and Allied Feltmakers Research Association, covering the year onded August 1959, stresses the addition to the research programme of a study of the shock-absorbing properties of felt and other matcrials, relative to protective headgear $(\mathrm{Pp}$. 20. Droylsden, Manchester: British Hat and Allied Feltmakers Research Association, 1959). Other work, which has largely been in continuation of work already projected, has included further study of the carrotting of fur, an examination of the fibre properties of rabbit fur from different sources and attempts to assess the feltability of vials by simple tests that could be carried out in the factory. A theoretical study of the free oseillation of the beam system of the felt-hardening machine suggested that the pattern of behaviour when the weight is adjusted reflects the changes in the amplitude and natural frequency of vibration of the beam assembly. The experimental programme with selected polyothanoxy assistants in dyeing felt showed that the assistants were selective in action with acid-levelling, acid-milling and both $1: 1$ and $1: 2$ premetallized colours and even in a particular class. In studics of the relation between the size and shape of the hat body required to make hats of a given size, brim-width and crown-shape, wide differences wero obscrved in the stretch pattern, and theoretical analysis indicated that the size and shape of hat bodies to give hats with a predetermined stretch pattern could be calculated if the geometry of the stretching could be stabilized. A review of the system of 'TDM indexes for measuring folt quality showed that the dependence of physical propertios upon form weight changed with time and that periodic revision of the indexes was required to avoid obsoles cence. A revised system has been proposed, while further work on frictional properties has provided an explanation of faults in felt which developed when bodies wero pounced wot. Lists of publications, officers and staff are included.

\section{"A Microsomal Malic Dehydrogenase"}

Dr. Kanneth H. Shull writes: "It has come to my attention that three orrors were made in my communication under this title in Nature, 183, 259-260, January 24, 1959. In both Figs. I and 2 the sentence in the legends referring to the abscisse should read "The abscissa is the reciprocal of the sub. strato (oxalacetate) concentration in $\mu M \times 1,000 / 3$ '. The value of the Michaelis constant, $K m$, line 24, column 2 , p. 259 , should read $4.66 \times 10^{-5} M$. The oxalacetate concentration, line 9 , p. 260 , should read $253 \mu M$. These errors arose from the fact that I plotted units of mass, micromoles of oxalacetate per cuvette, rather than units of concentration. Since each cuvette contained a total volume of $3.0 \mathrm{ml}$, these reciprocal values for concentration are too large by a value of $1,000 / 3$. The Michaelis constant which was determined graphically from Fig. 1 is thus too small by this same factor".

\section{Announcements}

Sir Gavin DE BeER will retire from the directorship of the British Museum (Natural History) on April 30. He will be succeeded by Dr. T. C. S. Morrison-Scott, at present director of the Science Museum, and previously on the staff of the British Museum (Natural History) in charge of the Marnmal Room.

No. 11, Vol. 5 (November 1959) of "The Bibliography of Scientific Publications of South and South East Asia", compiled jointly by Unesco Science Co-operation Offices for the area and published by Modec, National Physical Laboratory, New Delhi, contains a further 608 classified entries.

THE second Asian/Pacific Congress of Cardiology will be held in Melbourne during the last week in May. Further information can be obtained from Dr. A. E. Doyle, Alfred Hospital, Melbourne, S.1, Victoria, Australia.

LA Société do Chimie Physique is arranging a meeting on the Structure of Graphite and the Kinetics of its Reactions during May 31-June 3. Further information can be obtained from the Secrétaire Général de la Société de Chimie Physique, 10 Rue Vauquelin, Paris-Ve.

THe series of Summer Schools in Theoretical Chemistry which are hold annually at Oxford is being continued this year during September 10-24, under the direction of Prof. C. A. Coulson. Further particulars can be obtained from the Assistant Secretary, Dolegacy for Extra Mural Studies, Rewley House, Wellington Square, Oxford. Applications should be made before April 30 .

A sqmposium on Molecular Structure and Spectroscopy will bo held at the Department of Physics and Astronomy, Ohio State University, during June 1317. There will be discussions of the intorpretation of molecular spectroseopic data as woll as methods for obtaining such data. In addition, there will bo sessions devoted to those phases of spectroscopy of current interest. Further information can be obtained from Prof. R. A. Oetjen, Department of Physics and Astronomy, Ohio Stato University, Columbus 10, Ohio.

A Two-DAY conference, to be held in Philadelphia during April 28-29, on "The Role of Nuclear 1'ropulsion in our Future Merchant Marine", has been arranged by the Atomic Industrial Forum, an association of the atomic industry in the United States, in cooperation with the U.S. Atomic Encrgy Commission and the Maritime Administration. The provisional agenda includes : economics of nuclear ships, safety and liability problems, progress in foreign nations, and future prospects for the U.S. programme. Further information can be obtained from the Conference Manager, Atomic Industrial Forum, 3 East 54th Street, New York 22. 